\section{International Archives of \\ Allergy Immunology}

For the Author Index of No. 2-4, please see pp. 466-468
Alam, R. 7

Asakura, K. 37

Belohradsky, B.H. 74

Broadley, K.J. 51

Choi, H. 23

Dawson, C.A. 23

Erjefält, J.S. 67

Fukamachi, H. 44

Gleich, G.J. 44

Grote, M. 1

Gruber, R. 74

Hart, B.J. 15

Hazell, L.A. 15
Ide, Y. 44

Ishii, H. 44

Ishikawa, M. 44

Jäger, G. 74

Kaneoka, H. 30

Kataura, A. 37

Kelly, K.J. 23

Kita, H. 44

Koletzko, S. 74

Korsgren, M. 67

Korsgren, O. 67

Krauss-Etschmann, S. 74

Kurup, V.P. 23
Lewis, C.A. 51

Mills, K.L. 15

Minoguchi, K. 30

Oda, N. 30

Ogasawara, H. 37

Ohashi, H. 44

Persson, C.G.A. 67

Rickaby, D.A. 23

Saito, H. 37

Sakane, T. 30

Simon, H.-U. 7

Smith, W. 15
Sonmark, B. 67

Sundler, F. 67

Takei, M. 44

Takeno, M. 30

Thomas, W.R. 15

Warren, S.J. 51

Williams, B.D. 59

Xia, J.-Q. 23

Yamashita, N. 30

Yousaf, N. 59

\title{
Subject Index Vol. 118, 1999
}

For the Subject Index of No. 2-4, please see pp. 469-471

Airway hyperreactivity 23

\section{Anti-CD4 37}

Apoptosis 7

$\mathrm{BALB} / \mathrm{c}$ mice 23

B-cell deficiency 67

cDNA 15

Chemotaxis 44

Complement 59

Cord blood 44

Degranulation 44

Eosinophilia 37

Eosinophils 7, 23, 44

\section{Eotaxin 44}

Eur m 115

Eur m 215

Euroglyphus maynei 15

Fas receptor 7

Gamma scintigraphy 51

Histamine responsiveness 37

House dust mite 15

Hyaluronic acid 44

Hypersensitivity, immediate 67

IgE response 23

IL-4 knockout 23
Inflammation 7

${ }^{111}$ In-labelled leukocytes 51

Interleukin-5 7

Latex allergy 23

Lung inflammation 23

Lymphocyte migration, lungs 59

Monoclonal antibodies 59

Mononuclear cell 44

Nasal allergy 37

Nitric oxide 7

Opsonization 59

Ovalbumin-sensitized guineapigs 51
Plasma exudation 67

Response, early phase 67

-, late phase 67

Serum IgE 37

Signal transduction 7

99m TcMAA lung images 51

Th1 30

Th2 30

Tyrosine phosphorylation 30

ZAP-70 30

\section{KARGER}

(c) 1999 S. Karger AG, Basel

Fax +4161306 1234 